\title{
Inhibiting the Expression of a Classically Conditioned Behavior Prevents Its Extinction
}

\author{
David J. Krupa and Richard F. Thompson \\ Neuroscience Program, University of Southern California, Los Angeles, California 90089-2520
}

The underlying neuronal substrates and behavioral properties that might mediate extinction of the classically conditioned eye-blink response (CR) were examined. Four groups of rabbits were trained to perform the CR. Two of the groups then received either three or six sessions of tone-alone extinction training while the motor nuclei that mediate expression of the CR (facial nucleus and accessory abducens) were reversibly inactivated with microinjections of the GABA agonist muscimol. After these inactivation extinction sessions, rabbits received four more extinction sessions without inactivation. Two groups of controls received either three or six extinction sessions while saline vehicle was infused into the motor nuclei, followed by four sessions with no infusions. Saline infusions had no effect on extinction, and controls extinguished the CR normally over the first three to four sessions. In contrast, muscimol inactivation of the motor nuclei completely prevented any performance of CRs during the three or six inactivation extinction sessions. At the start of the four extinction sessions without inactivation, rabbits performed CRs at the same rate and amplitude as controls on their first extinction sessions. The muscimol rabbits then extinguished the CR normally over the four sessions without inactivation. In short, inactivation of the motor nuclei completely prevented any extinction of the eye-blink CR with no effect on subsequent extinction without inactivation. These results are discussed in terms of possible neuroanatomical loci that might mediate the extinction process as well as how effects of manipulating CR performance during extinction may affect the extinction process.

Key words: learning; memory; eye-blink; extinction; motor nuclei; classical conditioning

\section{Introduction}

It has seemed clear since Pavlov's (1927) original observations that extinction is not merely the fading away of a memory. The classical phenomena of spontaneous recovery and disinhibition, as well as reexposure to the reinforcer (Rescorla and Heth, 1975; Bouton, 1984), change in context (Bouton and Swartzentruber, 1991), sensitivity to changes in reinforcer value (Rescorla, 1995), and marked savings in reacquisition (Scavio and Thompson, 1979; Napier et al., 1992; Macrae and Kehoe, 1999), all argue that the originally learned associations are in some manner preserved during extinction training (Falls, 1998). The common explanation for these phenomena is that extinction induces new learning that somehow interferes with performance.

Pavlov (1927), Rescorla (1997), and others have emphasized the possibility that extinction results in an inhibitory association between a stimulus and a particular response, which would disrupt performance despite the continued presence of the original associations (Rescorla and Wagner, 1972; Rescorla, 1993). As Rescorla (1997) notes, one line of evidence favoring this view comes from the correlation between the amount of responding

Received June 13, 2003; revised Sept. 26, 2003; accepted Sept. 29, 2003.

This work was supported by National Science Foundation Grant IBN-9215069 and National Institute of Mental Health Grant 5P01-MH52194. We thank Dr. Christine Logan for assistance and comments during preparation of this manuscript.

Correspondence should be addressed to Dr. David J. Krupa at his present address: Department of Neurobiology, Box 3209, Room 333, Duke University Medical Center, Bryan Research Building, 101 Research Drive, Durham, NC 27710. E-mail:krupa@neuro.duke.edu.

Copyright $\odot 2003$ Society for Neuroscience $\quad$ 0270-6474/03/2310577-08\$15.00/0 that occurs in extinction and the amount of deterioration that the extinction experience produces. Procedures that reduce responding during extinction reduce performance loss (Holland and Rescorla, 1975), and procedures that augment responding during extinction amplify the loss resulting from non-reinforcement (Rescorla and Skucy, 1969; Wagner, 1971).

In the present experiments, we test this response-extinction hypothesis directly by preventing the occurrence of the conditioned response (CR) during conditioned stimulus (CS) tonealone extinction training, using classical conditioning of the rabbit eye-blink response. Although a great deal has been learned about the neural basis of acquisition of the conditioned eye-blink response (see Discussion), much less is known about the neural substrates of extinction. Thus, the conditioned eye-blink response would seem an ideal paradigm for neural analysis of extinction processes (Weiss et al., 1991; Krupa and Thompson, 1993; Perrett and Mauk, 1995; Gould and Steinmetz, 1996; Ramnani and Yeo, 1996). Previous work has shown that brainstem infusions of muscimol in the vicinity of the facial (FN) and accessory abducens (ACC) nuclei and adjoining reticular formation ipsilateral to the trained eye completely prevent reflex nictitating membrane (NM) extension and external eyelid closure in response to corneal stimulation (e.g., corneal air puff [unconditioned stimulus (US)]), and, of course, completely prevent occurrence of the conditioned eye-blink response (Krupa et al., 1996). Indeed, such infusions result in essentially complete inactivation of the ipsilateral facial musculature for a period of several hours. Animals trained under these conditions learn the condi- 
tioned eye-blink response to asymptote despite performing no CRs or unconditioned responses (URs) at all, as evidenced by post-inactivation performance (Krupa et al., 1996). Here we use an identical procedure for inactivating the motor nuclei during CS-alone extinction training after normal acquisition of the CR. In marked contrast to acquisition of the $\mathrm{CR}$, inactivation of the motor nuclei generating the behavioral response completely prevents extinction of the CR, as evidenced in post-inactivation extinction training.

\section{Materials and Methods}

Surgical procedures. Under aseptic surgical procedures, 39 New Zealand albino rabbits (Oryctolagus cuniculus, $\sim 2.5 \mathrm{~kg}$ at time of surgery) were each implanted with a chronic, stainless steel guide cannula (25 gauge, $0.65 \mathrm{~mm}$ outer diameter) fitted with an internal stainless steel stylet (to ensure patency) that extended $1.5 \mathrm{~mm}$ beyond the base of the guide cannula. Surgical procedures consisted of a midline incision through the scalp, retraction of the periostium, and a small craniotomy $(1.5 \mathrm{~mm}$ diameter) above the target brain region. The cannula-stylet assembly was slowly lowered through the brain so that the stylet tip was stereotaxically positioned dorsal and medial to the left facial nucleus: $3.2 \mathrm{~mm}$ anterior, 2.5. $\mathrm{mm}$ lateral, and $22 \mathrm{~mm}$ ventral to the lambda skull suture with lambda positioned $1.5 \mathrm{~mm}$ below bregma according to the stereotaxic atlas of McBride and Klemm (1968). This location was chosen to allow inactivation of both the FN and ACC with a single infusion of muscimol (see below). The cannulas were anchored to the skull using dental acrylic and three stainless steel skull screws. A small receptacle for attaching a mini-torque potentiometer and an air-puff nozzle during the behavioral training sessions was also cemented to the skull. A $1.0 \mathrm{~mm}$ loop of 6-o surgical suture (Ethilon) was placed in the apex of the left nictitating membrane. Surgical anesthesia consisted of ketamine $(60 \mathrm{mg} / \mathrm{kg})$, xylazine $(8 \mathrm{mg} / \mathrm{kg})$, and halothane (1-3\% in oxygen). All animals were treated in accordance with National Institutes of Health guidelines. All rabbits received $7 \mathrm{~d}$ postoperative recovery before any behavioral training.

Behavioral training procedures. In the experiments described below, the classically conditioned eye-blink response paradigm was used to examine the extinction process. After recovery, all rabbits were habituated to restraint in a Plexiglas restrainer and the behavioral recording apparatus for $1 \mathrm{hr}$. Rabbits were randomly assigned to one of four groups: 3-day muscimol, 3-day saline, 6-day muscimol, or 6-day saline (see below). Behavioral training sessions began the following day.

All rabbits underwent a four-phase training procedure (Fig. 1). The first phase of training comprised the acquisition phase in which all rabbits received four daily sessions of paired tone-air puff eye-blink conditioning. Each session consisted of 100 trials divided into 10 blocks of 10 trials. Each block of 10 trials consisted of one tone-alone trial, followed by four paired tone-air puff trials, followed by one air puff-alone trial, followed by four more paired tone-air puff trials. Intertrial interval varied randomly between 20 and $40 \mathrm{sec}$ (mean of $30 \mathrm{sec}$ ). Paired tone-air puff trials consisted of a tone CS $(350 \mathrm{msec}, 1 \mathrm{kHz}, 85 \mathrm{~dB})$ paired with a coterminating corneal air-puff US $\left(100 \mathrm{msec}, 2.1 \mathrm{~N} / \mathrm{cm}^{2}\right.$ pressure at the source). The tone was presented through a small loudspeaker placed 30 $\mathrm{cm}$ in front of the rabbit. The air puff was delivered from a $3 \mathrm{~mm}$ inner diameter tube positioned $1 \mathrm{~cm}$ from the center of the rabbit's cornea. Behavioral responses were measured with a minitorque potentiometer attached to the suture loop in the rabbits' left NM. Conditioned responses were defined as any $0.5 \mathrm{~mm}$ or greater extension of the NM occurring anytime between 35 and $250 \mathrm{msec}$ (US onset) after CS onset. On CS-alone trials, a CR was counted as any response $\geq 0.5 \mathrm{~mm}$ occurring anytime between 35 and $750 \mathrm{msec}$ after CS onset. On both paired and tone-alone trials, any response occurring between 0 and $35 \mathrm{msec}$ after CS onset was considered as an $\alpha$ response or a spontaneous response and was not counted as a CR. Unconditioned responses were defined as any movement of the NM within $500 \mathrm{msec}$ after US onset (the minimum resolvable movement was $100 \mu \mathrm{m}$ ).

To move on to the second phase of training, each rabbit was required to reach both of the following learning criteria: (1) perform at least eight
A

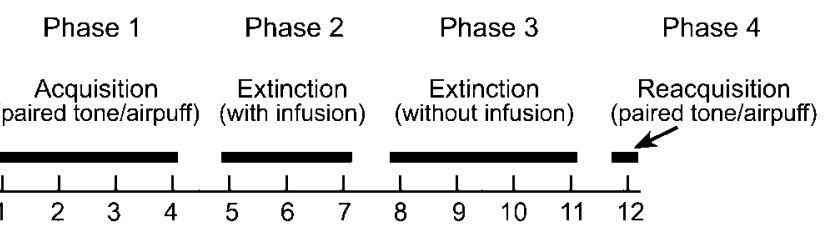

Session

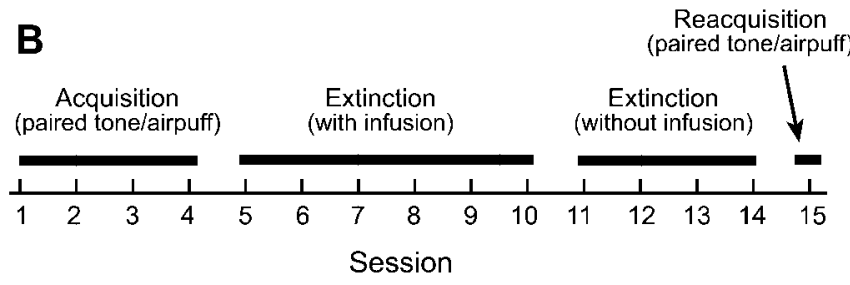

Figure 1. A, Training procedure for the 3-day muscimol and 3-day saline groups. Phase 1 consisted of four daily sessions of paired tone-air puff acquisition training. Phase 2 consisted of three tone-alone extinction sessions. One hour before each of these sessions, muscimol or saline was infused into the motor nuclei. Phase 3 consisted of four more tone-alone extinction sessions. No infusions were administered during these sessions. Phase 4 consisted of one session of paired tone-air puff reacquisition training. $B$, Training procedure for the 6-day muscimol and 6-day saline groups. Each of the four phases of training were the same as above, except that rabbits received six extinction sessions with infusions during phase 2 .

CRs within nine consecutive trials (excluding air puff-alone trials) by the end of the third acquisition session; (2) perform at least 80\% CRs during the fourth session. These criteria ensured that all rabbits had reached the same level of performance by the end of the fourth session. Rabbits that did not achieve both of these criteria were excluded from additional training and not included in data analysis.

The second phase of training consisted of tone-alone extinction training combined with very localized intracranial infusions of either the GABA agonist muscimol or saline-alone vehicle into the motor nuclei (see below). The muscimol infusions were designed to completely (and reversibly) inactivate the cranial motor nuclei (FN and ACC) and surrounding reticular formation essentially involved in expression of the eye-blink CR (Krupa et al., 1996). One group of rabbits (termed 3-day muscimol) received three daily sessions of the tone-alone extinction with infusions. Before each of these three sessions, each rabbit was infused with muscimol into the motor nuclei to inactivate these structures during these extinction sessions. The second group of rabbits (termed 3-day saline) also received three daily extinction sessions with infusions but were infused with saline-alone vehicle instead of muscimol into the motor nuclei. A third group of rabbits (termed 6-day muscimol) received six daily extinction sessions with infusions. Before each of these sessions, muscimol was infused into the motor nuclei. Finally, the fourth group of rabbits (termed 6-day saline) also received six daily extinction sessions, but saline-alone vehicle was infused into the motor nuclei.

The third phase of training consisted of four daily extinction sessions. During these extinction sessions, however, no infusions were administered. These sessions began $3 \mathrm{~d}$ after the final extinction session of phase 2 to ensure no lingering effects of the infusions. This phase of training was intended to examine the effects of the previous extinction training during which the motor nuclei were inactivated.

Each of the above extinction sessions consisted of 100 trials of tonealone presentations. The tone was exactly the same as in the previous acquisition sessions $(350 \mathrm{msec}, 1 \mathrm{kHz}, 85 \mathrm{~dB})$. Intertrial interval varied randomly between 20 and $40 \mathrm{sec}(M=30 \mathrm{sec})$. A conditioned response during these sessions was defined as any extension of the $\mathrm{NM} \geq 0.5 \mathrm{~mm}$ occurring anytime between 35 and $750 \mathrm{msec}$ after CS onset.

The final (fourth) phase of training consisted of one session of paired tone-air puff training (identical to sessions in phase 1, above) during which rabbits reacquired the eye-blink CR. 
Infusion procedures. One hour before each of the tone-alone extinction sessions in phase 2, rabbits in both the 3-day muscimol and 6-day muscimol groups received an infusion of muscimol (3.5 nmol in $0.4 \mu \mathrm{l}$ of isotonic saline vehicle; Sigma, St. Louis, MO) into the area of the FN and ACC. Rabbits in the 3-day saline and 6-day saline groups received an identical infusion of saline vehicle only. Infusion procedures involved removal of the internal stylet from the guide cannula, insertion of a stainless steel injector cannula ( 31 gauge, $0.21 \mathrm{~mm}$ outer diameter) that extended $1.5 \mathrm{~mm}$ below the base of the outer guide cannula, infusion of the drug or vehicle at $0.3 \mu \mathrm{l} / \mathrm{min}$, removal of the injector cannula $60 \mathrm{sec}$ after cessation of infusion, and, finally, reinsertion of the internal stylet. Because muscimol infusions eliminated all eye blinks on the eye ipsilateral to the infusion (see below), an artificial tear ointment was applied to the left eye of all rabbits (including saline controls) after infusion and again at the end of the extinction sessions of phase 2 to keep the cornea moist.

Histology. After the final training session, all rabbits were injected intravenously with a lethal dose of sodium pentobarbital and then perfused through the aorta with $0.9 \%$ saline, followed by a $10 \%$ Formalin solution. The position of the stylet tips was marked by passing $80 \mu \mathrm{A}$ (for $8 \mathrm{sec}$ ) of anodal current through a stainless steel lesioning electrode that had been lowered through the guide cannula to the exact depth of the stylet tip. This position is the same as that of the inner injection cannula tip when it was fully lowered during muscimol and saline infusions. The brains were then removed, embedded in an albumin gel, and stored in 10\% Formalin until they were sectioned $(80 \mu \mathrm{m})$ on a freezing microtome. The sections were stained with cresyl violet and Prussion blue, and the location of the stylet tip was determined.

Data analysis. CR frequencies were calculated for each session and averaged across rabbits within a group. In addition, a percentage of CR amplitude (\%CR-Amplitude) measure was calculated that scaled the response amplitudes during extinction sessions relative to those on the final acquisition day (see below). Group $\times$ session mixed ANOVA were calculated separately for 3 and $6 \mathrm{~d}$ groups for CR frequency in the acquisition phase and for both CR frequency and \%CR-amplitude measures for the extinction phases. Significant ANOVAs were followed by Newman-Keuls post hoc analyses when appropriate. A 0.05 significance level was used for all statistical tests.

\section{Results}

Of the 39 rabbits initially implanted with cannulas in the motor nuclei, five failed to reach the learning criteria by the end of the acquisition phase of training (eight CRs in nine consecutive trials and at least $80 \%$ CRs on the fourth acquisition session). These animals were, therefore, excluded from additional training and analysis. Additionally, muscimol infusions into the motor nuclei of six rabbits (two in the 3-day muscimol group and four in the 6-day muscimol group) during phase 2 (extinction training with infusion) failed to completely block performance of the previously acquired eye-blink CR. Each of these rabbits performed at least $36 \%$ CRs on at least one of the infusion sessions of this phase of training. Because muscimol infusions failed to completely block performance of the eye-blink CRs, these animals were excluded from additional analysis. With the exclusion of the above animals, the numbers of rabbits in each group that completed all four phases of training were as follows: 3 -day muscimol, $n=9$; 3 -day saline, $n=7$; 6-day muscimol, $n=6$; 6 -day saline, $n=6$.

Figure 2 shows the mean percentage of CRs for each group during the four acquisition sessions of phase 1 training. There were no differences between groups in rates of acquisition $\left(F_{(3,24)}<1\right)$, trials to criterion (eight CRs in nine consecutive trials; $F_{(3,24)}<1$ ), or percentage of CRs during session 4 of the acquisition phase of training $\left(F_{(3,24)}<1\right)$, indicating that rabbits in each group were performing at equivalent rates by the end of phase 1 . Trials to criterion (mean $\pm \mathrm{SE}$ ) for each group were as
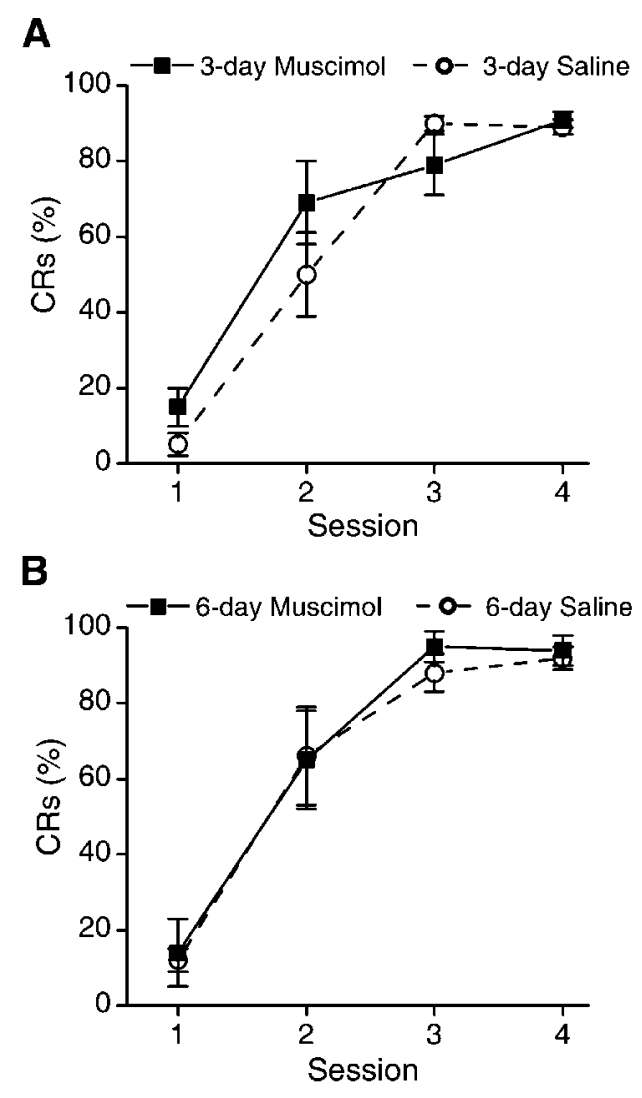

Figure 2. $A$, Mean \pm SEM percentage of CRs for the 3-day muscimol and 3-day saline groups over the four acquisition sessions of phase 1 . There were no differences between groups. $B$, Mean \pm SEM percentage of CRs for the 6-day muscimol and 6-day saline groups over the four acquisition sessions of phase 1 . There were no differences between groups.

follows: 3-day muscimol, $118 \pm 17$; 3-day saline, $137 \pm 17$; 6-day muscimol, $110 \pm 19 ; 6$-day saline, $112 \pm 19$.

Infusions of muscimol into the motor nuclei of rabbits in the 3-day muscimol and 6-day muscimol groups during phase 2 of training (tone-alone extinction) resulted in complete abolition of the eye-blink CR (Figs. 3, 4). Additionally, muscimol infusion also resulted in essentially complete inactivation of the ipsilateral facial musculature. The external eyelids were flaccid, the left ear hung down unsupported, and no vibrissae movements were observed on the side of infusion, results identical to those of a previous report that examined the effects of muscimol inactivation of the motor nuclei during acquisition of the eye-blink CR (Krupa et al., 1996). These effects on facial musculature became apparent 10-30 min after infusion of muscimol, lasted at least 3-4 hr, and completely disappeared within $6 \mathrm{hr}$ after infusion. These effects were localized entirely to the side of infusion. Also, muscimol infusions did not appear to affect the rabbits' ability to rotate their left eye if their bodies were rotated while restrained, suggesting that the extraocular muscles and the motor nuclei that control them were unaffected. No other effects of muscimol infusion on behavior were observed.

Infusions of saline-alone vehicle into the motor nuclei of rabbits in the 3-day saline and 6-day saline groups had no observable behavioral effects on any animal. Animals in both of these groups performed the CR robustly at the start of extinction training and extinguished the CR over the subsequent extinction sessions (Figs. 3, 4). As would be expected, there were no differences in rates of extinction between the saline control groups $\left(F_{(1,11)}<1\right)$. 


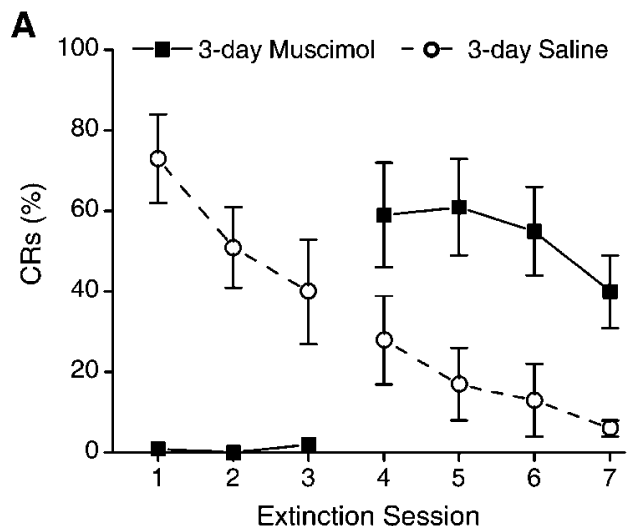

B

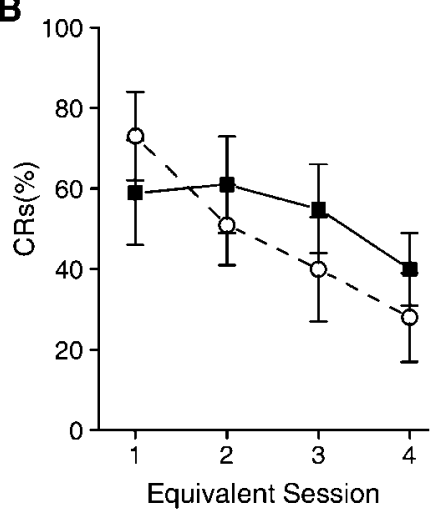

Figure 3. A, Mean \pm SEM percentage of CRs for the 3-day muscimol and 3-day saline groups over the two phases of extinction (with and without infusions). One hour before extinction sessions 1-3 (phase 2 of training), either muscimol or saline was infused. Infusion of muscimol completely abolished performance of the eye-blink CRs during sessions 1-3. No infusions were administered during sessions 4-6 (phase 3 of training). Saline control animals extinguish normally over the extinction sessions. In contrast, inactivation of the motor nuclei with muscimol during sessions $1-3$ completely prevented extinction of the $C R$, as evidenced by $C R$ performance on sessions $4-7$, which was significantly above saline controls. $B$, Mean \pm SEM percentage of CRs for extinction sessions 1-4 of the saline control group and sessions 4 -7 of the muscimol group (from $A$ ). There is no difference between groups, demonstrating that muscimol inactivation prevented extinction with no effects on subsequent extinction without muscimol.

On the first session of phase 3 of training (tone-alone extinction without infusions), rabbits in the 3-day muscimol group performed CRs at levels significantly higher than the 3-day saline control rabbits on that session $\left(t_{(14)}=-2.2\right)$ (Fig. 3A). The 3-day muscimol rabbits subsequently extinguished the $\mathrm{CR}$ over the following four sessions $\left(F_{(3,18)}=4.1\right)$. In contrast, $C R$ performance of the 3-day muscimol group on their first extinction sessions without inactivation, sessions $8-11$ (phase 3 , no muscimol infusions), did not differ significantly from performance of the 3-day saline control rabbits during their first extinction sessions, sessions 5-8 (termed equivalent sessions) $\left(F_{(1,14)}<1\right)$ (Fig. $\left.3 B\right)$.

Similarly, at the start of training on session 11 (first session without inactivation for the 6-day group), rabbits in the 6-day muscimol group performed CRs at levels significantly higher than rabbits in the 6-day saline control group $\left(t_{(10)}=-4.3\right)$ (Fig. $4 A$ ). There was no group difference in CR performance on sessions 11-14 for the 6-day muscimol group compared with sessions $5-8$ of the 6-day saline controls (equivalent sessions) $\left(F_{(1,10)}=1.8\right)$ (Fig. $\left.4 B\right)$. In summary, inactivation of the motor nuclei for either three or six extinction sessions completely prevented extinction of the eye-blink CR without affecting the ability to extinguish the $\mathrm{CR}$ in the absence of muscimol inactivation.
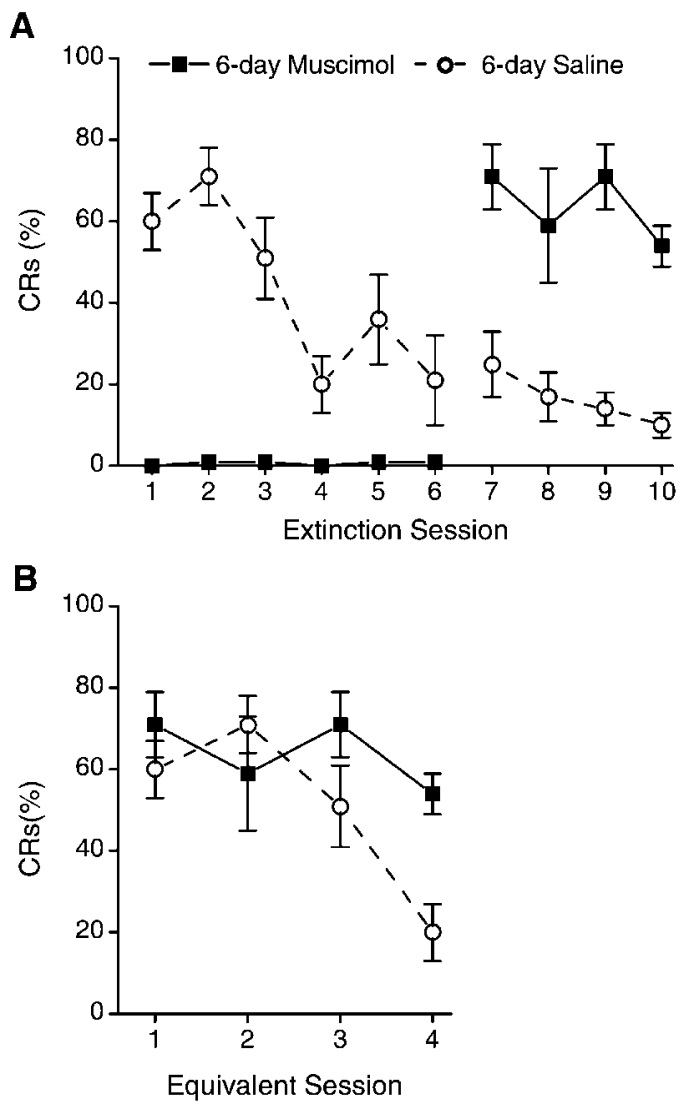

Figure 4. A, Mean \pm SEM percentage of CRs for the 6-day muscimol and 6-day saline groups over the two phases of extinction (with and without infusions). One hour before extinction sessions 1- 6 (phase 2 of training), either muscimol or saline was infused. Infusion of muscimol completely abolished performance of the eye-blink CRs during sessions $1-6$. No infusions were administered during sessions 7-10 (phase 3 of training). Saline control animals extinguish normally over the extinction sessions. In contrast, inactivation of the motor nuclei with muscimol during sessions $1-6$ completely prevented extinction of the $C R$, as evidenced by $C R$ performance on sessions $7-10$, which was significantly above saline controls. $B$, Mean \pm SEM percentage of CRs for extinction sessions 1-4 of the saline control group and sessions 7-10 of the muscimol group (from $A$ ). There is no significant difference between groups.

\section{Effects of inactivation on CR amplitude}

During extinction training, rabbits normally show reductions not only in the rate of performing the CR but also in the amplitude of the responses performed. Therefore, although the results described above demonstrate that inactivation of the motor nuclei completely prevented any reductions in the rate of CR performance, it remains possible that the amplitude of the CRs might have shown significant reductions as a result of extinction training with inactivation. To test whether the amplitude of CRs was affected by extinction training during inactivation, we also examined a measure termed \%CR-Amplitude. This measure accounts for changes in the amplitudes of CRs during extinction as well as changes in rates of responding. As such, \%CR-Amplitude provides a more meaningful measure of the process of extinction than simply examining changes in the rate of responding.

\%CR-Amplitude was calculated as follows. The mean peak $\mathrm{CR}$ amplitude (measured on tone-alone test trials) during session 4 (last acquisition session) was determined for each rabbit. For each rabbit, the amplitude of each CR performed on subsequent extinction sessions was divided by the mean peak CR amplitude of session 4 and multiplied by 100 . This yielded a value that represented the amplitude of each CR during the extinction ses- 


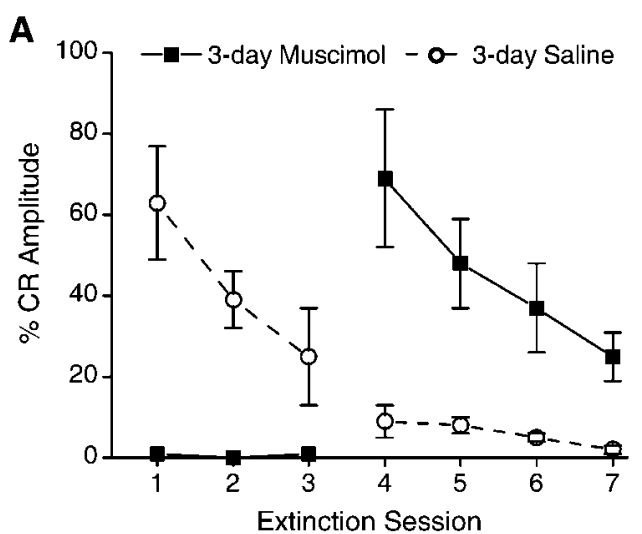

B

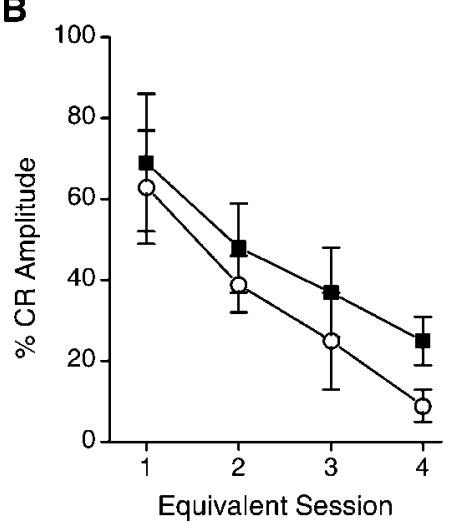

Figure 5. A, Mean \pm SEM percentage of (Rs for the 3-day muscimol and 3-day saline groups over the two phases of extinction (with and without infusions). The \%(R-Amplitude measure accounts for extinction-related changes in amplitude of CRs as well as changes in rates of responding (see Results). Infusions of muscimol or saline were administered on sessions 1-3, whereas no infusions were administered on sessions $4-7$. Inactivation of the motor nuclei with muscimol during sessions 1-3 completely prevented any decrement in CR amplitudes, as evidenced by performance on sessions $4-7$, which was significantly greater than saline controls. $B$, Mean \%CR-Amplitude ( \pm SEM) for extinction sessions 1-4 of the Saline control group and sessions $4-7$ of the Muscimol group. There is no difference between groups demonstrating that muscimol inactivation prevented extinction-related reductions in CR amplitude with no effects on subsequent extinction without muscimol.

sions as a percentage of the amplitude of the CR performed at the end of the acquisition sessions. Then the mean percentage of CR amplitude for each extinction session was calculated for each animal. In other words, the amplitudes of all responses during each extinction session were normalized to the mean amplitude of the conditioned response on session 4 (last acquisition session). This provided a measure of how the CR amplitudes were affected by the extinction sessions with and without muscimol inactivations.

\%CR-Amplitude values for the 3-day extinction groups are shown in Figure 5. Inactivation of the motor nuclei prevented any decrement in \%CR-Amplitude: \%CR-Amplitude for the 3-day muscimol rabbits on session 8 (first session without inactivation) did not differ from that of the 3-day saline group on session 5 (first extinction session) $\left(t_{(14)}=-0.27\right)$. In contrast, the \%CRAmplitude values of the 3-day muscimol group on session 8 was significantly greater than that of the 3 -day saline group on session $8\left(t_{(14)}=-3.1\right)$. The rate of decrease of \%CR-Amplitude for the 3-day muscimol group over sessions 8-11 did not differ from that of the 3-day saline group over sessions $5-8\left(F_{(1,14)}<1\right)$ (Fig. $5 B)$.

There were also no significant differences in \%CR-Amplitude
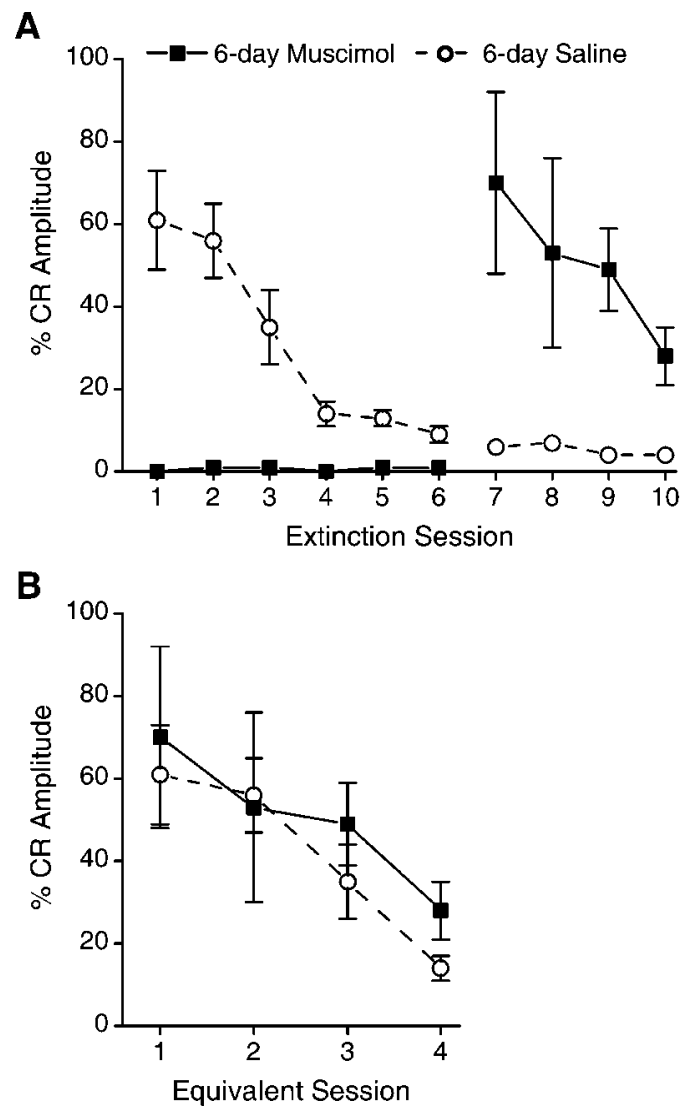

Figure 6. A, Mean \pm SEM percentage of CRs for the 6-day muscimol and 6-day saline groups over the two phases of extinction (with and without infusions). The \%CR-Amplitude measure accounts for extinction-related changes in amplitude of CRs, as well as changes in rates of responding (see Results). Infusions of muscimol or saline were administered on sessions 1-6, whereas no infusions were administered on sessions $7-10$. Inactivation of the motor nuclei with muscimol during sessions 1-6 completely prevented any decrement in CR amplitudes, as evidenced by performance on sessions $7-10$, which was significantly greater than saline controls. $B$, Mean \pm SEM percentage of CRs for extinction sessions 1-4 of the saline control group and sessions 7-10 of the muscimol group. There is no difference between groups, demonstrating that muscimol inactivation prevented extinction-related reductions in CR amplitude with no effects on subsequent extinction without muscimol.

between the 6-day muscimol rabbits on session 11 and the 6-day saline rabbits on session $5\left(t_{(10)}=-0.74\right)$ (Fig. 6A). There was, however, a significant difference in \%CR-Amplitude of the 6-day muscimol group and the 6-day saline group on session $11\left(t_{(10)}\right.$ $=-2.9$ ). As with the 3 -day muscimol group, the 6 -day muscimol group subsequently extinguished the CR over sessions 11-14 at rates similar to that of 6-day saline controls during sessions $5-8\left(F_{(1,10)}<1\right)$ (Fig. 6B).

In summary, inactivation of the motor nuclei for three or six extinction sessions completely prevented any extinction of the eye-blink CR. This was true whether the measure of extinction was percentage of CRs or whether the amplitudes of the responses were considered (\%CR-Amplitude).

\section{Reacquisition}

To ensure that the infusions of muscimol did not have any longterm detrimental effects on the ability to perform the CR, at the end of all extinction training, all rabbits received one session of paired tone-air puff training (parameters identical to the first four sessions). All animals robustly reacquired the CR during this session. Mean \pm SE percentage CRs for each group were as fol- 


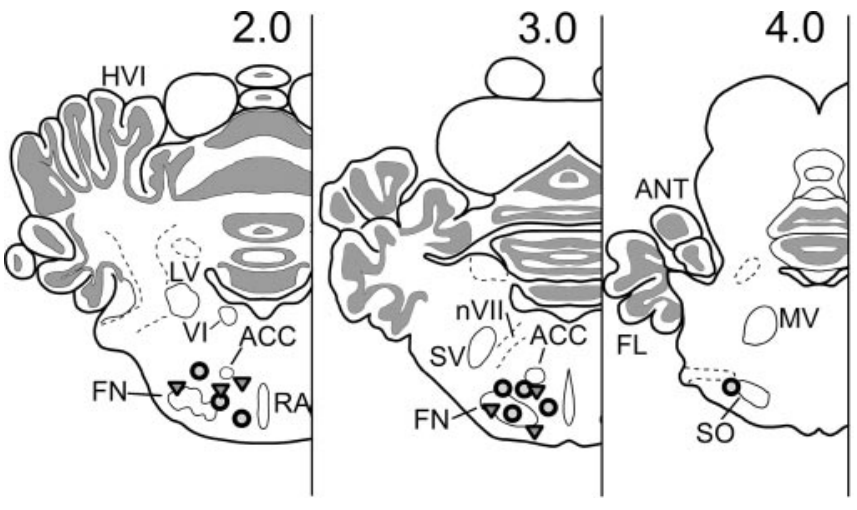

Figure 7. Cannula locations for each of the rabbits with effective muscimol inactivations. Open triangles, 3-day muscimol group; open circles, 6-day muscimol group. Numerals above each section represent distances (in millimeters) rostral to lambda in the stereotaxic plane. ACC, Accessory abducens nucleus; ANT, anterior lobe; FL, flocculus; FN, facial nucleus; HVI, hemispheric lobule VI; LV, lateral vestibular nucleus; MV, motor trigeminal nucleus; nVII, seventh nerve; RA, raphe nucleus; SO, superior olive; SV, sensory trigeminal; VI, abducens nucleus.

lows: 3-day muscimol, $69 \pm 9$; 3-day saline, $57 \pm 6$; 6-day muscimol, $78 \pm 7$; 6 -day saline, $67 \pm 10$. There were no significant differences in percentage of CRs between groups on this reacquisition session $\left(F_{(3,24)}=1\right)$.

\section{Histology}

Histological reconstructions of cannula placements in the motor nuclei are shown in Figure 7.

\section{Discussion}

Results of these experiments are clear: complete inactivation of the motor nuclei that generate the eye-blink CR and UR during CS alone extinction training, given over 3 or 6-day, completely prevents extinction, measured by either percentage CR or CR amplitude. In post-inactivation extinction training, extinction performance of the inactivation groups is identical to the initial extinction performance of the saline control groups; there is no savings in extinction. Consequently, inactivation of the motor nuclei during extinction training completely prevents the occurrence of extinction, a result strongly supportive of the responseextinction hypothesis (Rescorla, 1997). Because complete inactivation of these same motor nuclei during acquisition training has no deleterious effect at all on learning of the CR (Krupa et al., 1996), these current results provide powerful additional evidence that acquisition and extinction processes differ, not only in behavioral properties but also in neuronal substrates.

There are several possible physiological explanations why inactivation of the motor nuclei-CR performance, i.e., blocking response occurrence during extinction training, prevents extinction. Feedback from tactile stimulation of the cornea, from muscle and tendon receptors, reafference from the motor nuclei, or even from other regions are all possibilities. Such feedback could perhaps act via the inferior olive or even directly on the cerebellum (see below). Local changes in motor neuron excitability during extinction are yet another possibility (Woody, 1982).

The neural circuitry essential for acquisition and maintenance of the delay CR has been identified previously (Thompson and Krupa, 1994; Yeo and Hesslow, 1998; Nores et al., 2000; Steinmetz, 2000; Woodruff-Pak and Steinmetz, 2000; Christian and Thompson, 2003). Briefly, the CR pathway exits from the interpositus nucleus ipsilateral to the trained eye via the superior cerebellar peduncle to the red nucleus and subsequently via de- scending rubral pathways to the premotor and motor nuclei generating the CR. The CS pathway includes sensory relay nuclei and their projections via the pontine nuclei and other sources as mossy fibers to the cerebellum. The US pathway includes sensory (trigeminal) relays to the inferior olive and from there via climbing fibers to the cerebellum. The UR pathway includes both direct and indirect projections from the trigeminal nucleus to the motor nuclei generating the behavioral response and need not involve the cerebellum.

Using methods of reversible inactivation, we and others have presented very strong evidence that the memory trace(s) for eyeblink conditioning are stored in the cerebellum (Clark et al., 1992; Clark and Lavond, 1993; Krupa et al., 1993, 1996; Nordholm et al., 1993; Krupa and Thompson, 1995, 1997; Hardiman et al., 1996). In brief, inactivation of a localized region of the cerebellar anterior interpositus nucleus completely prevents performance and acquisition of the eye-blink CR, whereas inactivation of the superior cerebellar peduncle, the red nucleus, or the motor nuclei, although completely preventing performance of the CR, does not prevent learning at all. Subsequent postinactivation training results in learning with no savings at all after interpositus inactivation but fully asymptotic performance of the CR after training during inactivation of the efferent structures.

The present findings may require a reevaluation of some current literature concerned with brain substrates of extinction in eye-blink conditioning. Thus, Yeo and associates (Hardiman et al., 1996; Ramnani and Yeo, 1996) report that reversible inactivation of the interpositus nuclear region with muscimol during extinction training prevented CS alone extinction of the eyeblink CR. Because inactivation of the interpositus completely prevents performance of the behavioral CR, their results may be attributable simply to this fact, i.e., may have nothing directly to do with the neural processes of extinction.

A key issue concerns the role of cerebellar structures in extinction of the conditioned eye-blink response, particularly in terms of residual plasticity that could account for the extreme savings in reaquisition. Current evidence would seem to suggest the cerebellar cortex, the interpositus nucleus, or both as candidates. To date, recording of single- and multiple-unit activity in the critical region of the anterior interpositus nucleus shows neuronal responses that are essentially isomorphic (except for latency) with the behavioral conditioned response over both acquisition and maintenance of the CR (McCormick and Thompson, 1984; Berthier and Moore, 1990; Steinmetz, 1990).

Gould and Steinmetz (1996) reported that multi-unit activity in the interpositus correlated closely with the behavioral CR over both acquisition and extinction, showing complete absence of increased activity when the CR was fully extinguished. In contrast, multi-unit activity in cerebellar cortex increased over acquisition but did not decrease much during extinction of the CR, thus implicating the cortex for residual plasticity. Although several different patterns of responses were seen for identified single Purkinje neurons, some 13 Purkinje cells showed increased responses over training and did not decrease over extinction. Such increased Purkinje neuron activity could promote inhibition of interpositus activity in extinction.

Perrett and Mauk (1995) and Garcia et al. (1999) reported that, under certain conditions, lesions of the anterior lobe of cerebellar cortex in well trained animals can prevent extinction of the behavioral CR. Garcia et al. (1999) argue that neuronal plasticity occurs in both cerebellar cortex and interpositus with training, as suggested many years ago (Thompson, 1986). However, they argue further that plasticity in the interpositus is controlled 
by input from the cortex and that residual plasticity persists in the interpositus after extinction.

In support of the interpositus hypothesis, Medina et al. (2001) reported that picrotoxin infusion in the interpositus nucleus revealed short-latency CRs during training and also revealed the presence of such short-latency CRs after $45 \mathrm{~d}$ of extinction training, when no CRs occurred in the absence of picrotoxin, suggesting that the memory may be preserved in the interpositus nucleus. These results are puzzling because earlier work showed that infusion of picrotoxin in the interpositus in well trained animals impaired and abolished the CR in a dose-dependent manner with no appearance of short-latency CRs (Mamounas et al., 1987). Infusion of picrotoxin in the interpositus during training completely prevents learning of the CR (Bao et al., 2002). Medina et al. (2001) failed to include a control group that received the initial five acquisition training sessions followed only by CS-alone test trials $45 \mathrm{~d}$ later, i.e., with no intervening extinction training. Furthermore, they did not give untrained animals $45 \mathrm{~d}$ of tone-alone exposures, an essential control for non-associative effects. If the memory is indeed preserved in the interpositus, unit recordings should reveal it, and, to date, they do not (Gould and Steinmetz, 1996).

Perhaps the most straightforward neuronal instantiation of Pavlov's and Rescorla's inhibitory process in extinction would involve an increase in cerebellar cortical inhibition of interpositus neurons during extinction training, attributable in turn to feedback from the behavioral response, a possibility that is amenable to test.

Lesions of the appropriate region of the inferior olive (dorsal accessory olive), a part of the essential US reinforcing pathway, completely prevent learning and, if made in well trained animals, result in behavioral extinction of the CR with continued paired CS-US training [McCormick et al., 1985; Voneida et al., 1990 (limb flexion conditioning)]. Medina et al. (2002) recently replicated this result pharmacologically, infusing the AMPA receptor antagonist 1,2,3,4-tetrahydro-6-nitro-2,3-dioxo-benzo[f]quinoxaline-7-sulfonamide in the inferior olive in trained animals, which also yielded extinction with continued paired training. There is a direct GABAergic projection from the interpositus to the inferior olive that serves to inhibit US activation of the olivary climbing fibers in well trained animals (Nelson et al., 1989; Sears and Steinmetz, 1991; Hesslow and Ivarsson, 1996). Blocking this inhibitory pathway by infusion of picrotoxin in the inferior olive prevents this inhibition, thus allowing US activation of climbing fibers to the cerebellum in well trained animals, i.e., US-evoked complex spikes in Purkinje neurons (Kim et al., 1998). Such infusions during the compound training phase in the blocking paradigm completely prevent blocking (Kim et al., 1998). Medina et al. (2002) reported that such infusions of picrotoxin in the inferior olive also prevent CS alone extinction. In the present context, feedback from the occurrence of the behavioral CR may be necessary for normal inferior olive function in extinction.

It is possible that extracerebellar systems are also involved in the extinction process. Neurons in the hippocampus become massively engaged during acquisition of the eye-blink CR (Berger et al., 1976; Disterhoft et al., 1986). Although the hippocampus does not appear to play a key role in acquisition of the standard delay CR, there is evidence that it plays a role in extinction. Thus, Akase et al. (1989) trained and overtrained rabbits in a standard delay eye-blink CR and then gave them 80 CS-alone retention (extinction) trials. Animals with hippocampal lesions showed virtually no extinction in this test period compared with normal and neocortical lesion controls.
Finally, we note that, in another well characterized form of basic associative learning, fear conditioning, the neuronal substrates of acquisition, and extinction appear to differ at both systems and molecular levels (Bailey et al., 1999; Quirk et al., 2000; Lattal and Abel, 2001; Herry and Garcia, 2002).

\section{References}

Akase E, Alkon DL, Disterhoft JF (1989) Hippocampal lesions impair memory of short delay conditioned eye blink in rabbits. Behav Neurosci 103:935-943.

Bailey DJ, Kim JJ, Sun W, Thompson RF, Helmstetter FJ (1999) Acquisition of fear conditioning in rats requires the synthesis of mRNA in the amygdala. Behav Neurosci 113:276-282.

Bao S, Chen L, Kim JJ, Thompson RF (2002) Cerebellar cortical inhibition and classical eyeblink conditioning. Proc Natl Acad Sci USA 99:1592-1597.

Berger TW, Alger BE, Thompson RF (1976) Neuronal substrate of classical conditioning in the hippocampus. Science 192:483-485.

Berthier NE, Moore JW (1990) Activity of deep cerebellar nuclear cells during classical conditioning of nictitating membrane extension in rabbits. Exp Brain Res 83:44-54.

Bouton ME (1984) Differential control by context in the inflation and reinstatement paradigms. J Exp Psychol Anim Behav Process 10:56-74.

Bouton ME, Swartzentruber D (1991) Sources of relapse after extinction in Pavlovian and instrumental learning. Clin Psychol Rev 11:123-140.

Christian KM, Thompson RF (2003) Neural substrates of eyeblink conditioning: acquisition and retention. Learn Mem, in press.

Clark RE, Lavond DG (1993) Reversible lesions of the red nucleus during acquisition and retention of a classically conditioned behavior in rabbits. Behav Neurosci 107:264-270.

Clark RE, Zhang AA, Lavond DG (1992) Reversible lesions of the cerebellar interpositus nucleus during acquisition and retention of a classically conditioned behavior. Behav Neurosci 106:879-888.

Disterhoft JF, Coulter DA, Alkon DL (1986) Conditioning-specific membrane changes of rabbit hippocampal neurons measured in vitro. Proc Natl Acad Sci USA 83:2733-2737.

Falls WA (1998) Extinction: a review of theory and evidence suggesting that memories are not erased with non-reinforcement. In: Learning and behavior therapy (O’Donohue W, ed), pp 205-229. Boston: Allyn \& Bacon.

Garcia KS, Steele PM, Mauk MD (1999) Cerebellar cortex lesions prevent acquisition of conditioned eyelid responses. J Neurosci 19:10940-10947.

Gould TJ, Steinmetz JE (1996) Changes in rabbit cerebellar cortical and interpositus nucleus activity during acquisition, extinction, and backward classical eyelid conditioning. Neurobiol Learn Mem 65:17-34.

Hardiman MJ, Ramnani N, Yeo CH (1996) Reversible inactivations of the cerebellum with muscimol prevent the acquisition and extinction of conditioned nictitating membrane responses in the rabbit. Exp Brain Res 110:235-247.

Herry C, Garcia R (2002) Prefrontal cortex long-term potentiation, but not long-term depression, is associated with the maintenance of extinction of learned fear in mice. J Neurosci 22:577-583.

Hesslow G, Ivarsson M (1996) Inhibition of the inferior olive during conditioned responses in the decerebrate ferret. Exp Brain Res 110:36-46.

Holland PC, Rescorla RA (1975) The effect of two ways of devaluing the unconditioned stimulus after first- and second-order appetitive conditioning. J Exp Psychol Anim Behav Process 1:355-363.

Kim JJ, Krupa DJ, Thompson RF (1998) Inhibitory cerebello-olivary projections and blocking effect in classical conditioning. Science 279:570-573.

Krupa DJ, Thompson RF (1993) Effects of reversible lesions on extinction of the rabbits classically conditioned eyeblink response. Soc Neurosci Abstr 19:999.

Krupa DJ, Thompson RF (1995) Inactivation of the superior cerebellar peduncle blocks expression but not acquisition of the rabbit's classically conditioned eye-blink response. Proc Natl Acad Sci USA 92:5097-5101.

Krupa DJ, Thompson RF (1997) Reversible inactivation of the cerebellar interpositus nucleus completely prevents acquisition of the classically conditioned eye-blink response. Learn Mem 3:545-556.

Krupa DJ, Thompson JK, Thompson RF (1993) Localization of a memory trace in the mammalian brain. Science 260:989-991.

Krupa DJ, Weng J, Thompson RF (1996) Inactivation of brainstem motor nuclei blocks expression but not acquisition of the rabbit's classically conditioned eyeblink response. Behav Neurosci 110:219-227.

Lattal KM, Abel T (2001) Different requirements for protein synthesis in 
acquisition and extinction of spatial preferences and context-evoked fear. J Neurosci 21:5773-5780.

Macrae M, Kehoe EJ (1999) Savings after extinction in conditioning of the rabbit's nictitating membrane response. Psychobiology 27:85-94.

Mamounas LA, Thompson RF, Madden JT (1987) Cerebellar GABAergic processes: evidence for critical involvement in a form of simple associative learning in the rabbit. Proc Natl Acad Sci USA 84:2101-2105.

McBride RL, Klemm WR (1968) Stereotaxic atlas of the rabbit brain, based on the rapid method of photograpy of frozen, unstained sections. Commun Behav Biol 2:175-215.

McCormick DA, Thompson RF (1984) Neuronal responses of the rabbit cerebellum during acquisition and performance of a classically conditioned nictitating membrane-eyelid response. J Neurosci 4:2811-2822.

McCormick DA, Steinmetz JE, Thompson RF (1985) Lesions of the inferior olivary complex cause extinction of the classically conditioned eyeblink response. Brain Res 359:120-130.

Medina JF, Garcia KS, Mauk MD (2001) A mechanism for savings in the cerebellum. J Neurosci 21:4081-4089.

Medina JF, Nores WL, Mauk MD (2002) Inhibition of climbing fibres is a signal for the extinction of conditioned eyelid responses. Nature 416:330-333.

Napier RM, Macrae M, Kehoe EJ (1992) Rapid reacquisition in conditioning of the rabbit's nictitating membrane response. J Exp Psychol Anim Behav Process 18:182-192.

Nelson BJ, Adams JC, Barmack NH, Mugnaini E (1989) Comparative study of glutamate decarboxylase immunoreactive boutons in the mammalian inferior olive. J Comp Neurol 286:514-539.

Nordholm AF, Thompson JK, Dersarkissian C, Thompson RF (1993) Lidocaine infusion in a critical region of cerebellum completely prevents learning of the conditioned eyeblink response. Behav Neurosci 107:882-886.

Nores WL, Medina JF, Steele PM, Mauk MD (2000) Relative contributions of cerebellar cortex and cerebellar nucleus to eyelid conditioning. In: Eyeblink classical conditioning: animal models (Woodruff-Pak DS, Steinmetz JE, eds). Boston: Kluwer Academic.

Pavlov IP (1927) Conditioned reflexes: an investigation of the physiological activity of the cerebral cortex. London: Oxford UP.

Perrett SP, Mauk MD (1995) Extinction of conditioned eyelid responses requires the anterior lobe of cerebellar cortex. J Neurosci 15:2074-2080.

Quirk GJ, Russo GK, Barron JL, Lebron K (2000) The role of ventromedial prefrontal cortex in the recovery of extinguished fear. J Neurosci 20:6225-6231.

Ramnani N, Yeo CH (1996) Reversible inactivations of the cerebellum prevent the extinction of conditioned nictitating membrane responses in rabbits. J Physiol (Lond) 495:159-168.
Rescorla RA (1993) Inhibitory associations between $S$ and $R$ in extinction. Anim Learn Behav 21:327-336.

Rescorla RA (1995) Full preservation of a response-outcome association through training with a second outcome. Q J Exp Psychol B 48:252-261.

Rescorla RA (1997) Response-inhibition in extinction. Q J Exp Psychol B 50:238-252.

Rescorla RA, Heth CD (1975) Reinstatement of fear to an extinguished conditioned stimulus. J Exp Psychol Anim Behav Process 1:88-96.

Rescorla RA, Skucy JC (1969) Effect of response-independent reinforcers during extinction. J Comp Physiol Psychol 67:381-389.

Rescorla RA, Wagner AR (1972) A theory of Pavlovian conditioning: variations in the effectiveness of reinforcement and nonreinforcement. In Classical conditioning: II. Current research and theory (Black A, Prokasy WF, eds), pp 64-99. New York: Appleton-Century-Crofts.

Scavio MJ, Thompson RF (1979) Extinction and reacquisition performance alternations of the conditioned nictitating membrane response. Bull Psychon Soc 13:57-60.

Sears LL, Steinmetz JE (1991) Dorsal accessory inferior olive activity diminishes during acquisition of the rabbit classically conditioned eyelid response. Brain Res 545:114-122.

Steinmetz JE (1990) Neural activity in the cerebellar interpositus nucleus during classical NM conditioning with a pontine stimulation CS. Psychol Sci 1:378-382.

Steinmetz JE (2000) Brain substrates of classical eyeblink conditioning: a highly localized but also distributed system. Behav Brain Res 110:13-24.

Thompson RF (1986) The neurobiology of learning and memory. Science 233:941-947.

Thompson RF, Krupa DJ (1994) Organization of memory traces in the mammalian brain. Annu Rev Neurosci 17:519-549.

Voneida TJ, Christie D, Bogdanski R, Chopko B (1990) Changes in instrumentally and classically conditioned limb-flexion responses following inferior olivary lesions and olivocerebellar tractotomy in the cat. J Neurosci 10:3583-3593.

Wagner AR (1971) Elementary associations. In: Essays in neo-behaviourism: a memorial volume to Kenneth W. Spence (Kendler HH, Spence JT, eds), pp 187-213. New York: Appleton-Century-Crofts.

Weiss C, Logan CG, Thompson RF (1991) Effects of cerebellar cortical lesions on extinction and reacquisition of NM conditioning in rabbits. Soc Neurosci Abstr 17:869.

Woodruff-Pak DS, Steinmetz JE (2000) Eyeblink classical conditioning: animal models. Boston, MA: Kluwer Academic.

Woody CD (1982) Memory, learning, and higher function. New York: Springer.

Yeo CH, Hesslow G (1998) Cerebellum and conditioned reflexes. Trends Cogn Sci 2:322-330. 